of life cannot be interpreted except in terms of their past history, and the past must be studied in the light of the present.

Physical theory holds that space implies time; it needs time for development. Time, on the other hand, implies space; neither can exist without the other. Pattern is secondary to these primary phenomena; it must have both time and space in which to develop. Whitehead summed up the position in the famous phrase, "There is no Nature at an instant".

For more than two thousand years, naturalists have proceeded on the basis of an infinite threedimensional space, which endured by the summation of a succession of instants. Now they are told that there is no Nature, alive or dead, at any given instant, that duration is essential to existence, that events can be precisely located neither in space nor in time, and that everything is in a state of movement or flux. In short, they have to adjust their ideas to an entirely different set of physical presuppositions.

Current taxonomy is founded on the old assumptions, and, so long as it is concerned with the position and motion of organisms, it continues to function fairly well, particularly when dealing with the present, or with apparently isolated events in the past. Difficulties arise when one attempts to fit organisms in locomotion into a framework which was not designed for their reception. The result is to distort either the component representing position or else that repre. senting velocity.

The amount of distortion is largely dependent on the skill and judgment of the taxonomer; but it is always considerable. It is the result of an endeavour to discuss velocity in terms of position, and its effects are illustrated in Simpson's arrangement of the Equidæ. There the lineage which leads from Hyracotherium to Equus is divided among three sub. families, each containing a segment of the main stem as well as of one or more side branches. The classi. fication is the fruit of great experience and mature judgment; but its author had no course open to him other than to represent a single biological entity of one kind under the guise of three entities of another kind. In effect, orthodox taxonomy emphasizes the static side of biology, and therefore fails to give adequate representation to the organism's velocity or evolution.

Osborn's formal classification of the Proboscidea is not generally accepted because, as he himself admitted, it differs more from all existing arrangements than these do from the Linnæan system. His method was to isolate as many ascending lineages as the evidence appeared to warrant, and to call each lineage a subfamily. 'Larger gaps in the record broke the lineages into larger sections or 'genera', and minor gaps broke up the 'genera' into 'species'; there are other complications of secondary importance.

The fundamental difference is that Osborn constructed the first classification of organisms in locomotion, and, although he does not appear to have been aware of the fact, the first classification at all conformable with the modern physical background of biology. For this reason the Osbornian principles are worthy of closer study than they have hitherto received, since they may foreshadow the taxonomy of the future. Evolutionary biology now has the evolutionary physical background it requires as a basic assumption, and sooner or later its primary discipline must adapt itself to the changed conditions.

\section{THE GENERAL CIRCULATION OF THE ATMOSPHERE $+2 \%$}

$\mathrm{O}$ $\mathrm{N}$ May 18 a meeting of the Royal Meteorological Society was held to discuss the problem of the changing patterr 0 flatge scale flow in the atmosphere, usually known as the 'general circulation'. In opening the discussion, $\mathrm{D}$. E. Eady pointed out that even on a lan stale, chen the motion has been smoothed of such small-scale and transient irregularities as tra oring depressions and anticyclones, fronts, etc., we were not concerned with a problem of steady motion; 5-day mean charts smooth out most of the travelling disturbances (including the 'long waves' which travel, on the average, nearly a complete wave-length during this period), but differ very considerably among themselves even for the same time of year. Only when we take means over a long period does the mean flow approximate to that shown on climatological charts. The general behaviour is reminiscent of small-scale turbulent motion (frictionally induced) in aerodynamics, means over longer and longer periods bringing out disturbances of longer and longer wave-length, finally yielding a quasi-steady mean flow. Although the mechanism by which large turbulent disturbances in the atmosphere are continually regenerated (to make up for frictional dissipation) differs from that by which small-scale aerodynamic turbulence is maintained, there is a broad similarity between the two types of turbulence. Just as in aerodynamics, we cannot divorce the study of the mean motion from that of the turbulent disturbances, since these are mutually determining.

In Dr. Eady's view, empirical evidence points to the necessity for adopting such an attitude. Calculations of the radiation balance in different latitudes, such as those carried out by Sir George Simpson, showed that there must be, on the average, a trans. port of heat from low to high latitudes. Since the upper troposphere shows a negative radiation balance, there must also be upward transport of heat. Although part of the former might be effected by ocean currents and part of the latter by small-scale convection, the main transport is probably associated with the large-scale disturbances, that is, it is eddytransport. Only in limited regions can steady mean currents, such as the monsoon circulations, effect part of the transport. Besides poleward transport of heat, we also have poleward transport of westerly momentum; for the climatological charts show a belt of easterly winds in low latitudes, the 'trades', and westerly winds in middle latitudes, which have to be maintained against friction. This, acting alone, would eventually destroy the motion completely, and the persistence of these mean winds requires an effect. ive transport of momentum which can only be brought about by disturbances, not by steady currents.

The poleward and upward transport of heat, that is, from a warm 'source' to a cold 'sink', is a thermodynamic necessity if solar radiant energy is to be transformed into kinetic energy to maintain the motion of the atmosphere against friction. The precise mechanism by which this transformation takes place is only just beginning to be understood. It is clear that if new disturbances are to develop from time to time we must show that the mean motion is unstable. Dr. Eady referred to a forthcoming paper of his in Tellus (1, No. 2, May 1949 ; Stockholm), in which it is shown that steady 
uniform motion of a rotating baroclinic fluid, such as the atmosphere, is unstable in almost all circumstances, even when convectively stable. Previous attacks on the problem of dynamical instability when there are no velocity discontinuities (velocity discontinuity always gives rise to instability, at least on a small scale) have lacked generality. They discussed essentially 'overturning' in a vertical plane and obtained the well-known criterion, negative absolute vorticity in isentropic surfaces. But another type of disturbance exists, corresponding to 'overturning' in a plane sloping upwards toward the pole at an angle less than that of the isentropic surfaces. Long-wave disturbances are almost always unstable. In each case there exists one particular disturbance which grows faster than any other and becomes apparent on synoptic charts by a process analogous to 'natural selection'. The long waves observed are the form of breakdown, by this process, of the whole troposphere. Smaller secondary disturbances are the form of breakdown, by a similar process, of baroclinic cloud sheets, that is, 'frontal' regions. 'There is good numerical agreement between theory and observation regarding wave-length, wave-velocity, growth-rate, and structure of these disturbances. Dr. Eady concluded by discussing briefly some of the difficulties encountered in attempting to extend the theory to make possible the computation of weather changes (more precisely, of most probable changes), and also mentioned one way in which orography causes irregularity in the mean flow at all levels.

In the absence of Mir. C. H. B. Priestley, Dr. A. G. Forsdyke gave an account of his paper, "Heat Transport and Zonal Stress Between Latitudes" (Quart. J. Roy. Met. Soc., 75, 28; Jan. 1949). Mir. Priestley was concerned with estimating, from empirical evidence given by radio-sonde winds and temperatures, the actual poleward transport of heat and momentum referred to above. The flux of heat can conveniently be divided into (i) a component associated with the mean flow; (ii) a 'toroidal' (meridional) component associated with net poleward flow at low levels, equatorward flow at high levels; (iii) an eddy-flux associated with transient disturbances. Since for this purpose heat may be regarded as a conservative quantity, the eddy-flux of heat is proportional to the correlation between poleward motion and excess heat content. It is convenient to divide the latter into sensible heat (measured by temperature), and latent heat of water vapour. It would be desirable if this eddy-transport could be evaluated at a large number of stations, and it was one of Mir. Priestley's objects to set an example by computing it for one station, namely, Larkhill, England. He found that transport of heat in latent form is about the same as that in sensible form. He also noted a curious negative transport, that is, towards the equator, in the upper troposphere, while in the stratosphere the transport is towards the poles. He also computed the toroidal flux, but there appears to be some doubt (expressed by Mr. J. S. Sawyer and Dr. Eady) regarding the validity of his formula.

Momentum (or angular momentum) is not a conservative quantity for individual particles. Nevertheless, the total transport of momentum across a circle of latitude over all heights is given by Jeffreys's formula, which is, in fact, simply the total Reynolds's stress. Mr. Priestley evaluated separately components which can be regarded (formally) as eddyflux and toroidal flux. The latter is considerably the smaller. He found that the total flux is in the right direction in winter, but much smaller and often negative in summer. On the whole, it is of about the right order of magnitude.

Mr. Priestley has not evaluated the transport associated with the mean flow. Evaluation at one station would be of little value, since on integration round a circle of latitude the contributions would largely cancel.

Dr. R. C. Sutcliffe gave an illustrated account of a preliminary attempt to sort out types of largescale flow empirically. $\mathrm{He}$ suggested that the atmosphere can 'solve its own equations' in a variety of ways, yielding types of flow pattern which persist for considerable periods ; from time to time it 'flips over' relatively quickly from one basic pattern to another. $\mathrm{He}$ did not indicate, however, why this takes place, except to suggest that it is associated with seasonal changes.

Sir David Brunt emphasized the importance of ealculations such as those of Mr. Priestley. $\mathrm{He}$ referred to several early calculations, including those of Mir. E. Gold, indicating radiative cooling of the upper troposphere. He suggested that some meteorological problems cannot yet be solved because of ignorance regarding the correct boundary conditions. Mir. J. S. Sawyer emphasized the importance of travelling disturbances in determining the general circulation. Prof. P. A. Sheppard, referring to strong winds (and hence appreciable energy in spite of low density) in the upper stratosphere, indicated the possibility of events at these levels affecting the circulation below in the long run.

Mir. A. W. Brewer said that accurate humidity measurements, with the Dobson-Brewer frost-point hygrometer, suggest, on account of the extreme dryness of the stratosphere, that the troposphere and stratosphere are two different worlds. Nieasurements of helium content show no appreciable variation up to at least $22 \mathrm{~km}$., so that there must be some diffusion across the tropopause; but it cannot be large or the very steep gradient of vapour content would be destroyed. He suggested that stratospheric air in middle latitudes originates above the tropopause in low latitudes, where even saturated air has very little vapour content. He indicated some of the difficulties involved in this theory, since it requires rather rapid radiative cooling in the air subsiding along the tropopause ; further, if purely zonal flow is postulated, angular momentum should be conserved (contrary to observation) during transit.

In his concluding remarks Dr. Eady referred to the changes in the tropospheric motion to be expected if the mean stratospheric temperature changes, with consequent alteration in the mean height of the tropopause.

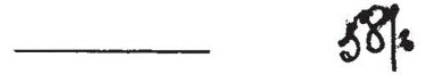

\section{HETEROGENEOUS CATALYSIS}

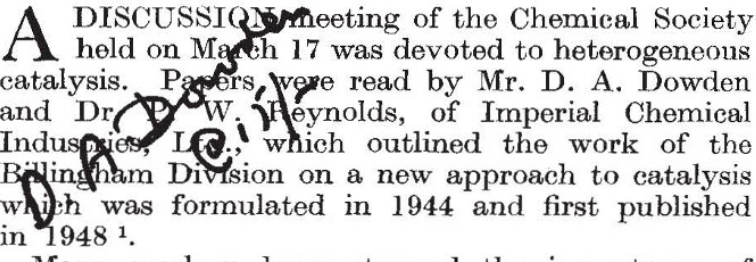

Many workers have stressed the importance of relationships between the dimensions of reacting molecules and the crystal parameters of the catalysts 